\title{
In situ evaluation of European eel counts and length estimates accuracy from an acoustic camera (ARIS)
}

\author{
Raphaël Lagarde ${ }^{1,2, *}$, Jason Peyre ${ }^{1,2}$, Elsa Amilhat ${ }^{1,2}$, Manon Mercader ${ }^{1,2}$, François Prellwitz ${ }^{1,2}$, \\ Gaël Simon ${ }^{1,2}$ and Elisabeth Faliex ${ }^{1,2}$ \\ ${ }^{1}$ Université de Perpignan Via Domitia, Centre de Formation et de Recherche sur les Environnements Méditerranéens, UMR 5110 , \\ Perpignan F 66860, France \\ ${ }^{2}$ CNRS, Centre de Formation et de Recherche sur les Environnements Méditerranéens, UMR 5110, Perpignan F 66860, France
}

Received: 24 September 2020 / Accepted: 11 November 2020

\begin{abstract}
Despite the increasing use of acoustic cameras in fish ecology and fisheries studies, the quantification of biases associated with this method have received little attention. In this note, we used data collected from an ARIS acoustic camera, positioned in a channel linking a lagoon to the sea, to quantify differences in European eel (Anguilla anguilla) counts and size estimates made by two experienced operators. Count estimates made from 58 videos were highly consistent between the two operators $\left(R^{2}=0.99\right)$, although statistically different. Compared to the known sizes for the 82 eels, sizes estimated manually from video were underestimated. The resulting mean error percentages were significantly different between the two operators $(-3.9 \% \pm 8.5(\mathrm{SD})$ and $-6.6 \% \pm 8.9)$. This error percentage was significantly influenced by the known size of the eels but not by the detection range. Our results highlighted the importance of taking into account the biases in counts and size estimates in fish ecology and fisheries studies based on acoustic cameras. These biases have to be quantified and, if possible, corrected using similar protocols as described in this study, when multiple operators analyse acoustic videos or when comparing the results from different studies.
\end{abstract}

Keywords: Anguilla anguilla / dual-frequency sonar / fish counting / hydroacoustics / migratory fish

Résumé - Évaluation in situ de la précision des estimations de nombres et de taille d'anguilles européennes à partir d'une caméra acoustique (ARIS). Malgré l'utilisation de plus en plus généralisée des caméras acoustiques pour les études d'écologie des poissons et de leurs pêcheries, les biais potentiels inhérents à cette méthode ont été très peu décrits. Dans cette note, nous avons utilisé des données issues d'une caméra acoustique ARIS, positionnée dans un chenal reliant une lagune à la mer, pour quantifier les différences d'estimations de nombre et de taille d'anguilles européennes (Anguilla anguilla) réalisées par deux opérateurs expérimentés. Les nombres estimés à partir de 58 vidéos étaient très similaires entre les deux opérateurs $\left(R^{2}=0,99\right)$ même si ces derniers étaient significativement différents. Les mesures manuelles de tailles réalisées pour 82 anguilles européennes à partir des images des vidéos étaient légèrement sousestimées par rapport à la taille réelle de ces anguilles. Les pourcentages d'erreur moyens des mesures, de $-3.9 \pm 8.5$ (SD) et $-6.6 \% \pm 8.5$, étaient significativement différents entre les deux opérateurs. Pour chaque opérateur, le pourcentage d'erreur était significativement influencé par la taille des anguilles mais pas par la distance de détection. Nos résultats ont mis en évidence les biais d'estimation de nombres et de taille des poissons liés à l'utilisation des caméras acoustique dans les études d'écologie des poissons et de leurs pêcheries. Ces biais devraient être quantifiés et, si possible, corrigés en utilisant des protocoles similaires à ceux décrits dans notre étude, lorsque les vidéos sont analysées par plusieurs opérateurs ou que des résultats issues d'études différentes sont comparés.

Mots clés : Anguilla anguilla / sonar bi-fréquence / comptage de poissons / hydroacoustique / poissons migrateurs

\footnotetext{
*Corresponding author: raphael.lagarde@univ-perp.fr
} 
Acoustic cameras are increasingly used in fish ecology and fisheries studies (Becker and Suthers, 2014; Boulêtreau et al., 2020) because they are quantitative, non-invasive and can be used at night and/or with excessive turbidity (Martignac et al., 2015). However, one of the main limits of acoustic cameras is the identification of multiple fish at the species level (Martignac et al., 2015). This limit can be overcome for freshwater eels (Anguilla spp.), as they can be distinguished based on their swimming behaviour and/or morphology (Lenihan et al., 2019). No tool currently exists to automatically identify species based on these particular features (but see Yin et al., 2020), which prevents the use of an automated approach when species-specific data are needed (Capoccioni et al., 2019). The manual processing of videos is labourintensive and time consuming. For example, Lenihan et al. (2019) estimated that the individual observation and measurement of 587 European eels (Anguilla anguilla) for 42 nights (approximately $670 \mathrm{~h}$ of videos) took $105 \mathrm{~h}$. Consequently, video processing is commonly performed by multiples operators (Briand et al., 2016). However, consistency between operators, for European eels and other fish species has received little attention. This topic needs to be addressed to take into account operator-induced differences or trends in the data when multiple operators process the videos and/or when comparing results from different studies.

Fish length can be estimated manually from videos using acoustic camera software. This data can be useful to differentiate species (Becker and Suthers, 2014; Grote et al., 2014), adults from juveniles of the same species (Doehring et al., 2011) or in the case of European eels, males from females (Vollestad, 1992). Several studies estimated the reliability of length estimates based on acoustic videos by comparing the known size (usually total length $\mathrm{L}_{\mathrm{T}}$ ) of different species to the length estimate from acoustic video $\left(\mathrm{L}_{\mathrm{AV}}\right)$ in the laboratory (Hightower et al., 2013; Zhang et al., 2014; Cook et al., 2019; Daroux et al., 2019) or in the field (Burwen et al., 2010). These studies concluded that $\mathrm{L}_{\mathrm{AV}}$ could be either over estimated or under estimated compared to $\mathrm{L}_{\mathrm{T}}$ depending on the species (Hightower et al., 2013), its size (Daroux et al., 2019), the orientation of the fish compared to the camera and the detection range (Cook et al., 2019). This emphasizes the need to specifically describe the difference between $\mathrm{L}_{\mathrm{T}}$ and $\mathrm{L}_{\mathrm{AV}}$ for each target species. Furthermore, Daroux et al. (2019) detected an operator effect on the difference between $\mathrm{L}_{\mathrm{T}}$ and $\mathrm{L}_{\mathrm{AV}}$.

In this context, we aimed to assess the consistency of in situ eel counts and size estimates made by two experienced operators involved in the analysis of the videos captured by an Adaptive Resolution Imaging Sonar (ARIS, Explorer 1800, Sound Metrics) acoustic camera. The ARIS acoustic camera was installed in a channel which links a lagoon (Bages-Sigean, Southern France) to the Mediterranean Sea (see online supplementary material for details; Fig. S1) to monitor the movements and migrations of critically endangered European eels (Jacoby et al., 2015) at the yellow and silver stages between the lagoon and the sea. The acoustic camera was positioned in the narrowest part of the channel, which is $53 \mathrm{~m}$ wide in total, with a mean depth of $3.5 \mathrm{~m}$. It was fixed to a pontoon pillar at a depth of $3 \mathrm{~m}$ and at a distance of $20 \mathrm{~m}$ from the closest bank in order to record horizontally toward the opposite bank and perpendicularly to the flow direction. It was set at a frequency of $1.8 \mathrm{MHz}$ which provided a range of

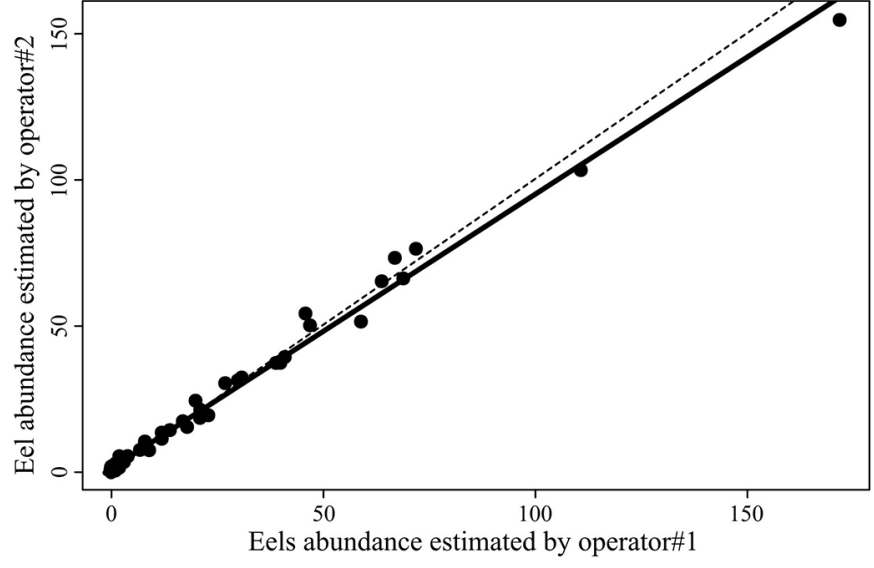

Fig. 1. Orthogonal regression (solid black line) of the estimated eel counts from $15 \mathrm{mn}$ videos $(N=58)$ made by operators\#1 and \#2. The dashed line represents the line with a null intercept and a slope of one.

images at a distance of only $14-15 \mathrm{~m}$ from the camera but facilitated the identification of eels based on their behaviour and morphology. At this frequency, the camera's field of view was $28^{\circ}$ horizontally and $14^{\circ}$ vertically and covered approximately $10 \%$ of the surface of the channel in this section. From 26 October 2018 to the 30 March 2020, the camera continuously recorded a succession of $15 \mathrm{mn}$ videos for $24 \mathrm{~h}$ a day.

To evaluate the consistency of count estimates, eels were enumerated by two experienced operators through the analysis of several $15 \mathrm{mn}$ videos using ARIS fish software (Sound Metrics). Among the 11332 videos analysed from October 2018 to March 2019, 58 were subsampled and blindly analysed by both operators (without knowing the number of eels estimated by the other operator). These videos were selected to cover the full range of eel counts from a minimum of zero eels per video to a maximum of more than 150 eels per video. The eel counts estimated by the two operators were compared using orthogonal regression (Fig. 1). The slope and intercept of the orthogonal regression between the estimates made by the two operators were significantly different from 1 and 0 , respectively. The intercept $\pm 95 \%$ confidence interval was $1.5 \pm 1.0$ and the slope was $0.94 \pm 0.05$. These results indicate that the estimates of eel counts made by the two operators were significantly different (Panfili et al., 2002). However, when considering the 56 videos for which the number of eels counted was less than 100 , the intercept was not different from 0 $(0.53 \pm 1.0)$ and the slope was not different from $1(1.0 \pm 0.04)$. Moreover, the Pearson correlation coefficient of these two regressions $\left(R^{2}\right)$ was $\geq 0.98$, highlighting a strong consistency between the estimates of the two operators. In conclusion, a single operator count was sufficient when the number of eels counted per video was lower than 100 . However, when more than 100 eels per video were counted, it appears appropriate to use counts from two operators and to use the mean of the two counts in the database.

To assess the in situ accuracy of eel length estimates based on measurements from the acoustic videos, $\mathrm{L}_{\mathrm{AV}}$ made manually by the two operators using ARIS fish software were compared to the known $\mathrm{L}_{\mathrm{T}}$ of same eels previously 
measured. A total of 170 eels were captured by professional fishermen in the studied lagoon from October to December 2019 using fyke nets as described in Amilhat et al. (2008). They were kept in bag nets placed in the lagoon for 3-5 days. On the day of the experiment the eels were considered in good general condition and liveliness. These eels were anesthetized in $0.3 \mathrm{ml} . \mathrm{L}^{-1}$ of eugenol (diluted at $30 \%$ in alcohol) and measured $\left(\mathrm{L}_{\mathrm{T}}\right)$ to the closest $\mathrm{mm}\left(\mathrm{L}_{\mathrm{T}}\right.$ ranging from 27.4 to $96.0 \mathrm{~cm}$ ). Eels recovered from anaesthesia in individually labelled net bags submerged in the channel. When fully awaken, the eels were released one by one in front of the camera using a $10 \mathrm{~cm}$ diameter and a $5 \mathrm{~m}$ long PVC pipe. The use of the PVC pipe ensured that eels were released in the camera's field of view and individually identified by an operator who watched the videos in real time and recorded the exact time each individual eel exited the PVC pipe (Fig. S2). Eels were released from the pontoon or from a boat at distances ranging from 3.0 to $13.5 \mathrm{~m}$ from the camera. Between 12 and 79 eels were released on five different dates (i.e. 4, 16 and 28 October; 3 and 5 December 2019) to include different environmental conditions (turbidity, flow velocity) known to influence the quality of video. All dates were aggregated in the following analyses. When an eel was not observed to have exited the pipe, the pipe was removed from the water to ensure that the eel was no longer inside to avoid misidentification of individuals. Among the 170 eels released, 138 were successfully identified and measured using the ARIS fish software by the two operators. Relying on personal experience, each operator selected the frame in which to make the most accurate measurement of the eel. Despite the recommendation of Daroux et al. (2019) who recommended three measurements of the same fish be made in order to improve measurement accuracy, we measured each eel only once as this is the standard procedure used (due to time limitation) when processing videos with a large number of eels, as observed in our data. For each measurement, both operators attributed a qualitative estimate to the accuracy of the $\mathrm{L}_{\mathrm{AV}}$ estimation (i.e. poor, fair and good). Most of the poor quality estimates were obtained when eels swam vertically downward after exiting the pipe, making it impossible to observe their entire body length on videos. Other eels swam more or less perpendicularly to the camera in the direction of the flow or in the opposite direction. The following analyses focused on 82 eels, with known $\mathrm{L}_{T}$ ranging from 29.8 to $90.1 \mathrm{~cm}$, for which the $\mathrm{L}_{\mathrm{AV}}$ estimates were considered as "good" or "fair" by both operators. The mean ( \pm standard deviation) error percentage $\frac{\left(\mathrm{L}_{\mathrm{AV}}-\mathrm{L}_{\mathrm{T}}\right)}{\mathrm{L}_{\mathrm{T}}} \times 100$ (Boussarie et al., 2016) was $-6.6 \pm 8.9$ and $-3.9 \pm 8.5$ for operators $\# 1$ and $\# 2$, respectively. These low negative values indicate that $\mathrm{L}_{\mathrm{AV}}$ estimates are only slightly underestimated compared to the known $\mathrm{L}_{\mathrm{T}}$ of eels. This result confirmed the systemic bias in length estimates reported in other studies for different fish species based on acoustic videos made with DISON cameras (Hightower et al., 2013; Grote et al., 2014). The error percentages were significantly different between the two operators (pairwise $\mathrm{T}$ test of Student, $\mathrm{df}=81$, $p=0.001$, Fig. 2). It emphasizes the need to specifically correct $\mathrm{L}_{\mathrm{AV}}$ estimates made by different operators in studies focused on eels using acoustic cameras. The error percentage did not vary with the distance from the camera (Tab.1) but the underestimation of $\mathrm{L}_{\mathrm{AV}}$ compared to $\mathrm{L}_{\mathrm{T}}$ was greater for the biggest eels (Tab. 1 and Tab. 2). The effect of the interaction

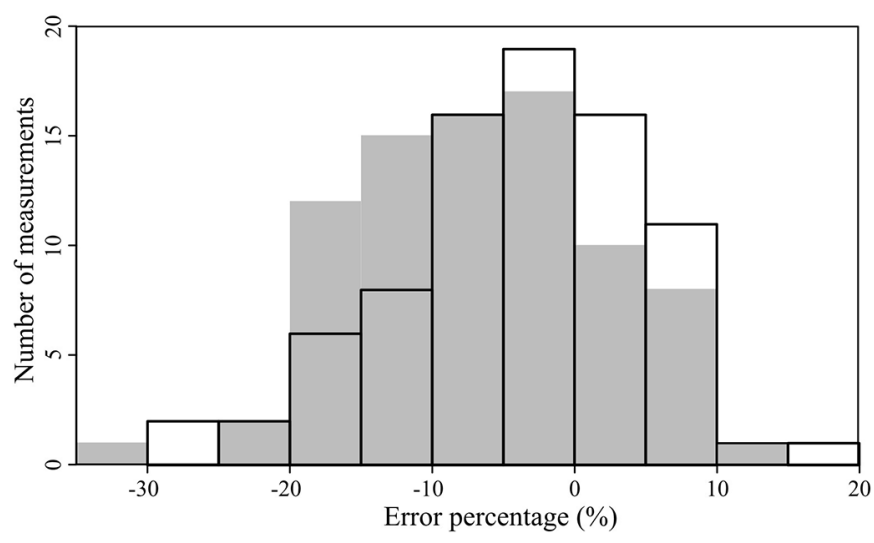

Fig. 2. Distribution of error percentages of the length estimates of 82 eels from the videos. The grey bars and the open bars with the black outline represent the distribution of error percentages for operators $\# 1$ and $\# 2$, respectively.

Table 1. Results of the linear regression analysing the percentage of error with $\mathrm{L}_{\mathrm{T}}$, the distance from the camera where $\mathrm{L}_{\mathrm{AV}}$ was estimated, the operator and the interactions between the operator and $\mathrm{L}_{\mathrm{T}}$, and the distance from the camera as explanatory variables.

\begin{tabular}{lll}
\hline Variable & $\mathrm{F}$ & $p$ \\
\hline $\mathrm{L}_{\mathrm{T}}$ & 19.46 & $<0.001$ \\
Distance from the camera & 0.93 & 0.33 \\
Operator & 4.69 & 0.03 \\
$\mathrm{~L}_{\mathrm{T}}$ : Operator & 0.62 & 0.43 \\
Distance from the camera: Operator & 2.64 & 0.11 \\
\hline
\end{tabular}

between $\mathrm{L}_{\mathrm{T}}$ and the operator on the error percentage was not significant $(p>0.05)$, meaning the decrease in error percentage with $\mathrm{L}_{\mathrm{T}}$ was not different among operators (Tab. 1; Fig. 3). The non-significant effect of the distance to the camera on $\mathrm{L}_{\mathrm{AV}}$ was previously described for DIDSON cameras in several species both in the field (Burwen et al., 2010) and under laboratory (Hightower et al., 2013) conditions. Hightower et al. (2013) also observed a slight overestimation of $\mathrm{L}_{\mathrm{AV}}$ compared to $\mathrm{L}_{\mathrm{T}}$ for small sized fish species $\left(20-30 \mathrm{~cm} \mathrm{~L}_{\mathrm{T}}\right)$, although for larger species, $\mathrm{L}_{\mathrm{AV}}$ tended to be underestimated. However, none of the tested species were anguilliform and these authors used different models of acoustic cameras. Our results support their conclusions but also specify the $\mathrm{L}_{\mathrm{AV}}$ estimates accuracy for European eels and other anguilliform species using videos from ARIS cameras. Based on our results, a way to minimize the effect of operators and to increase the accuracy of the eel measurements is to correct each $\mathrm{L}_{\mathrm{AV}}$ with the specific error percentages calculated for each operator and each size $\left(\mathrm{L}_{\mathrm{AV}}\right)$ class (Tab. 2).

To conclude, our study demonstrates that eel counts and size estimates differed slightly but significantly when estimated from acoustic videos by two different experienced operators. Size estimates also differed when compared to known sizes for both operators. Although the quantification of these errors is probably specific to the model of acoustic camera used and to the studied species, they need to be 
Table 2. Mean $( \pm \mathrm{SD})$ error percentage made by operators $\# 1$ and $\# 2$ for different size $\left(\mathrm{L}_{\mathrm{T}}\right)$ classes of eels. The number $(N)$ of eels measured in each size class is specified.

\begin{tabular}{llll}
\hline & $\mathrm{L}_{\mathrm{T}}<45 \mathrm{~cm}(N=34)$ & $45 \mathrm{~cm} \leq \mathrm{L}_{\mathrm{T}}<60 \mathrm{~cm}(N=22)$ & $\mathrm{L}_{\mathrm{T}} \geq 60 \mathrm{~cm}(N=26)$ \\
\hline Operator\#1 & $-3.1 \pm 8.9$ & $-7.7 \pm 8.4$ & $-10.3 \pm 7.7$ \\
Operator\#2 & $-2.1 \pm 7.9$ & $-2.8 \pm 8.9$ & $-7.1 \pm 8.3$ \\
\hline
\end{tabular}

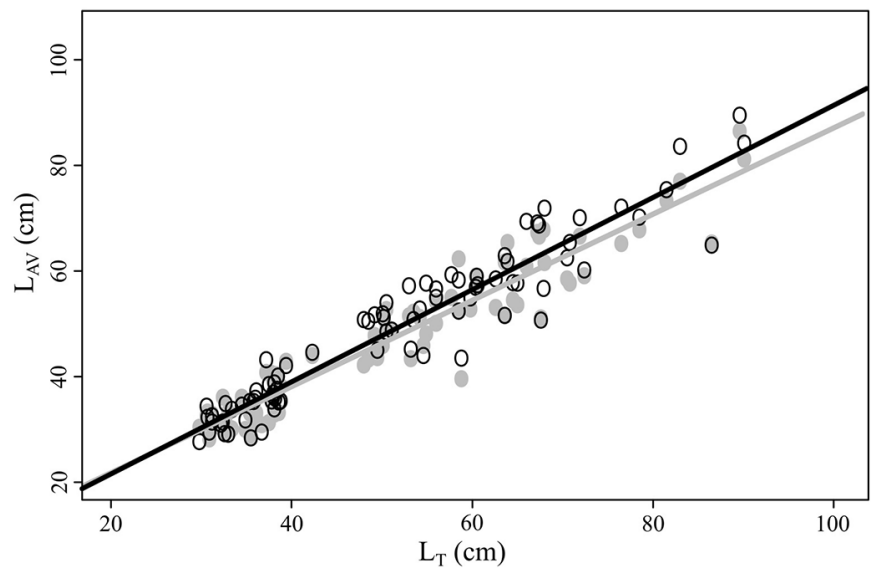

Fig. 3. Linear regression of the $\mathrm{L}_{\mathrm{AV}}$ estimates made by operators\#1 (grey line, $R^{2}=0.90$ ) and \#2 (black line, $R^{2}=0.91$ ) according to the known $\mathrm{L}_{\mathrm{T}}$ of 82 eels. The grey dots represent the $\mathrm{L}_{\mathrm{AV}}$ estimates made by operator\#1 whereas the open dots represent the $\mathrm{L}_{\mathrm{AV}}$ estimates made by operator\#2.

considered in any future fish ecology and fisheries studies to correct errors when multiple operators are involved and/or to allow comparisons between different studies. Based on our results, we recommend that the maximum threshold number of eels counted per video be defined (i.e. 100 eels per 15-min video in our study), above which two or more operators need to process the videos. Even if the potential error percentage is low, the $\mathrm{L}_{\mathrm{AV}}$ estimate accuracy could be improved by applying a correction coefficient based on the error percentage between $\mathrm{L}_{\mathrm{AV}}$ and $\mathrm{L}_{\mathrm{T}}$ made by each operator in each size class. This correction coefficient should be estimated for each study and each operator, following a similar protocol as presented in our study.

\section{Supplementary Material}

Supplementary Figure S1: Location of the studied lagoon: Bages-Sigean.

Supplementary Figure S2: Screenshots illustrating the field of view of the ARIS camera during the experiment.

The Supplementary Material is available at https://www.kmaejournal.org/10.1051/kmae/2020037/olm.

Acknowledgements. This study was conducted with the financial support of Agence de l'eau Rhône Méditerranée Corse (2-4 allée Lodz, 69363 Lyon cedex 07, France), Région Occitanie (201 avenue de la Pompignane, 34064 Montpellier cedex 02, France), Ministère de l'Agriculture et de l'Alimentation (Hôtel de Villeroy, 75007 Paris, France) and préfecture de la Région Occitanie (Place Saint-Etienne, 31038 Toulouse cedex 9, France). We are very thankful to the professional fishermen that provided the eels for the study and all of the people who assisted us during the study. Finally, we thank the three anonymous reviewers for their useful comments on a previous version of this paper and Jeanine Almany for her corrections and suggestions concerning the English language of the paper.

\section{References}

Amilhat E, Farrugio H, Lecomte-Finiger R, Simon G, Sasal P. 2008. Silver eel population size and escapement in a Mediterranean lagoon: Bages-Sigean, France. Knowl Manag Aquatic Ecosyst 5: 390-391.

Becker A, Suthers IM. 2014. Predator driven diel variation in abundance and behaviour of fish in deep and shallow habitats of an estuary. Estuar Coast Shelf Sci 144: 82-88.

Boulêtreau S, Carry L, Meyer E, Filloux D, Menchi O, Mataix V, Santoul F. 2020. High predation of native sea lamprey during spawning migration. Sci Rep 10: 1-9.

Boussarie G, Teichert N, Lagarde R, Ponton D. 2016. BichiCAM, an underwater automated video tracking system for the study of migratory dynamics of benthic diadromous species in streams. River Res Appl 32: 1392-1401.

Briand C, Sauvaget B, Eriau G. 2016. Suivi de la dévalaison d'anguilles argentées en 2014-2015 (troisième année) sur la Vilaine à l'aide d'un DIDSON [Technical report]. EPTB Vilaine $27 \mathrm{p}$.

Burwen DL, Fleischman SJ, Miller JD. 2010. Accuracy and precision of salmon length estimates taken from DIDSON sonar images. Trans Am Fish Soc 139: 1306-1314.

Capoccioni F, Leone C, Pulcini D, Cecchetti M, Rossi A, Ciccotti E. 2019. Fish movements and schooling behavior across the tidal channel in a Mediterranean coastal lagoon: an automated approach using acoustic imaging. Fish Res 219: 105318.

Cook D, Middlemiss K, Jaksons P, Davison W, Jerrett A. 2019. Validation of fish length estimations from a high frequency multibeam sonar (ARIS) and its utilisation as a field-based measurement technique. Fish Res 218: 59-68.

Daroux A, Martignac F, Nevoux M, Baglinière JL, Ombredane D, Guillard J. 2019. Manual fish length measurement accuracy for adult river fish using an acoustic camera (DIDSON). J Fish Biol.

Doehring K, Young RG, Hay J, Quarterman AJ. 2011. Suitability of Dual-frequency Identification Sonar (DIDSON) to monitor juvenile fish movement at floodgates. New Zeal J Mar Fresh Res 45: 413-422.

Grote AB, Bailey MM, Zydlewski JD, Hightower, JE. 2014. Multibeam sonar (DIDSON) assessment of American shad 
R. Lagarde et al.: Knowl. Manag. Aquat. Ecosyst. 2020, 421, 44

(Alosa sapidissima) approaching a hydroelectric dam. Can J Fish Aquat Sci 71: 545-558.

Hightower JE, Magowan KJ, Brown LM, Fox DA. 2013. Reliability of fish size estimates obtained from multibeam imaging sonar. $J$ Fish Wildl Manag 4: 86-96.

Jacoby DMP, Casselman JM, Crook V, DeLucia M-B, Ahn H, Kaifu K, Kurwie T, Sasal P, Silfvergrip AMC, Smith KG, Uchida K, Walker AM, Gollock MJ. 2015. Synergistic patterns of threat and the challenges facing global anguillid eel conservation. Glob Ecol Conserv 4: 321-333.

Lenihan ES, McCarthy TK, Lawton C. 2019. Use of an acoustic camera to monitor seaward migrating silver-phase eels (Anguilla anguilla) in a regulated river. Ecohydrol Hydrobiol 19: 289-295.

Martignac F, Daroux A, Bagliniere J-L, Ombredane D, Guillard J. 2015. The use of acoustic cameras in shallow waters: new hydroacoustic tools for monitoring migratory fish population. A review of DIDSON technology. Fish Fish 16: $486-510$

Panfili J, de Pontual H, Troadec H, Wright PJ. 2002. Manuel de sclérochronologie des poissons. Ifremer-IRD.

Vollestad LA. 1992. Geographic variation in age and length at metamorphosis of maturing European eel: Environmental effects and phenotypic plasticity. J Anim Ecol 61: 41-48.

Yin T, Zang X, Hou Z, Jacobson PT, Mueller RP, Deng Z. 2020. Bridging the gap between laboratory and field experiments in American eel detection using transfer learning and convolutional neural network. Proc 53rd HICSS 932-939.

Zhang H, Wei Q, Kang M. 2014. Measurement of swimming pattern and body length of cultured Chinese sturgeon by use of imaging sonar. Aquaculture 434: 184-187.

Cite this article as: Lagarde R, Peyre J, Amilhat E, Mercader M, Prellwitz F, Simon G, Faliex E. 2020. In situ evaluation of European eel counts and length estimates accuracy from an acoustic camera (ARIS). Knowl. Manag. Aquat. Ecosyst., $421,44$. 